\title{
VSC-HVDC for Frequency Support (a review)
}

DOI:

10.1049/cp.2017.0062

\section{Document Version}

Accepted author manuscript

Link to publication record in Manchester Research Explorer

\section{Citation for published version (APA):}

Fradley, J., Preece, R., \& Barnes, M. (2017). VSC-HVDC for Frequency Support (a review). In The 13th IET international conference on AC and DC Power Transmission https://doi.org/10.1049/cp.2017.0062

\section{Published in:}

The 13th IET international conference on AC and DC Power Transmission

\section{Citing this paper}

Please note that where the full-text provided on Manchester Research Explorer is the Author Accepted Manuscript or Proof version this may differ from the final Published version. If citing, it is advised that you check and use the publisher's definitive version.

\section{General rights}

Copyright and moral rights for the publications made accessible in the Research Explorer are retained by the authors and/or other copyright owners and it is a condition of accessing publications that users recognise and abide by the legal requirements associated with these rights.

\section{Takedown policy}

If you believe that this document breaches copyright please refer to the University of Manchester's Takedown Procedures [http://man.ac.uk/04Y6Bo] or contact uml.scholarlycommunications@manchester.ac.uk providing relevant details, so we can investigate your claim.

\section{OPEN ACCESS}




\title{
VSC-HVDC for Frequency Support (a review)
}

\author{
John Fradley, Robin Preece and Mike Barnes \\ School of Electrical and Electronic Engineering, The University of Manchester, M13 9PL, United Kingdom \\ E-mail:john.fradley@manchester.postgrad.ac.uk robin.preece@manchester.ac.uk; mike.barnes@manchester.ac.uk
}

Keywords: VSC-HVDC, Frequency Stability, Frequency Control, Islanded, MTDC.

\begin{abstract}
To reduce $\mathrm{CO}_{2}$ emissions produced by electricity generation, conventional fossil fuel power plants are being decommissioned. Renewable energy sources (RES) and interconnectors are replacing these old power plants but have different operating characteristics. A key concern as the conventional fossil fuel power plants are displaced is the reduction in system inertia. A reduction in system inertia will require faster control schemes to be implemented to prevent frequency and rate of change of frequency (ROCOF) limits from being exceeded. Frequency response schemes that can emulate inertia, often called synthetic inertia, are required and this will necessitate the need for fast controlled devices. VSCHVDC is a desirable interface option for the power levels and controllability required to provide synthetic inertia. This paper reviews supplementary frequency control schemes applied to VSC-HVDC and co-ordinated control strategies applicable to HVDC connected systems and islanded systems.
\end{abstract}

\section{Introduction}

In order to reduce greenhouse gas emissions, especially $\mathrm{CO}_{2}$, electricity generation will require significant decarbonisation. Approximately $32 \%$ of $\mathrm{CO}_{2}$ emissions in Great Britain are due to electricity generation [1]. To reduce the impact of $\mathrm{CO}_{2}$ emissions from electricity generation; renewable sources of generation are replacing fossil fuel power plants. Integration of RES brings new challenges as they do not possess identical characteristics to fossil fuel power plants. RES are intermittent and increasingly connected using power electronic converters which limits the inherent support offered to the network.

An increasing concern for the transmission system operators is the reduction of system inertia that is occurring by displacing fossil fuel power plants [2]. Consequences of reduced system inertia if left unmitigated will be high consumer costs and a system that is less stable with the potential for blackouts. The events described in [3] highlight the unfortunate sequence of events that lead to a blackout occurring. With reduced system inertia, occurrences such as lines tripping could increase the load on certain generators suddenly and cause a fast ROCOF. This could then lead to the disconnection of generation which could be catastrophic.

Fast frequency support that can emulate the characteristics of traditional inertia (inherent in synchronous generation) is therefore required to reduce the rate of change of frequency. The provision of this fast frequency support is often called synthetic inertia. VSC-HVDC has the potential to facilitate frequency support due to its characteristics. VSC-HVDC is already used with wind power plants (WPPs), interconnectors and electrical storage. Evolving from these applications in the future are multi terminal DC (MTDC) networks and islanded networks containing power electronic interfaced generation. Through local and coordinated control strategies, VSCHVDC can be used for frequency support. A future low inertia power system will inevitably require enhanced control strategies that provide fast sophisticated frequency support.

This paper provides a review of supplementary local control strategies for VSC-HVDC and coordinated control strategies/techniques applicable for the control of resources within MTDC grids or islanded systems. This is not intended as an exhaustive list of control strategies but of key VSCHVDC frequency control concepts.

\section{Supplementary VSC Frequency Control}

In order to utilise VSC-HVDC for frequency response, control alterations are required that generally involve the addition of a supplementary control loop. The supplementary control loops provide additional references (or modifications of setpoints) for use in the upper level control of the cascaded control structure shown in Fig.1 [4]. This section provides an overview of frequency response control schemes applicable to VSC-HVDC. Note that all diagrams presented are not an exact replication from their referenced source due to signal and convention harmonisation applied for the purpose of consistency in this document.

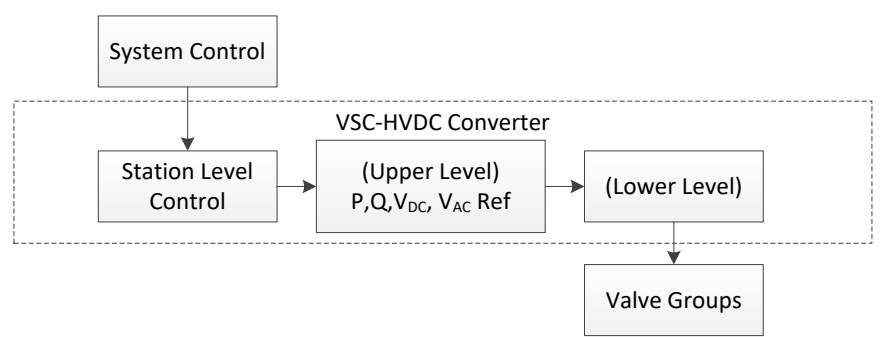

Fig. 1: Control hierarchy for VSC-HVDC, adopted from [4].

\subsection{Proportional control}

A proportional control output is proportional to the input signal which produces a linear response and is often commonly termed droop control as displayed in Fig. 2 (a). Standard values for the slope of the proportional droop control are typically between $3-5 \%$. 
Droop control schemes are often implemented with a deadband or saturation limits to provide the required operating characteristics. A saturation block prevents the output from exceeding set limits as displayed in Fig. 2(b) and a deadband prevents the operation of the output during a given range of the input as described in [5] and displayed in Fig.2(c). Precise values for these nonlinearities are dependent on system conditions and operating regimes as well as the device capabilities. All of the following controllers can be implemented using saturation, deadband or combination of both. For simplicity, these have been neglected from the following diagrams of control structures.

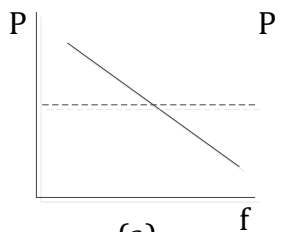

(a)

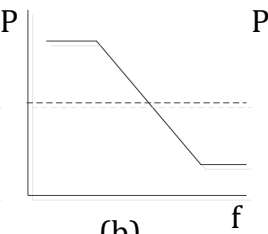

(b) (c)

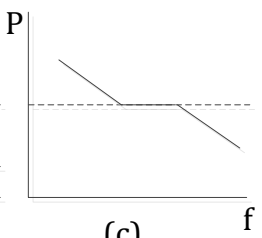

Fig. 2: (a) proportional (b) saturation (c) deadband.

Throughout, values for gain $(\mathrm{K})$ and time constant $(\tau)$ would be different for each figure, but for simplicity generic symbols are used along with $s$ to denote a derivative action and $1 / s$ to denote an integral action.

Droop control can be implemented into a VSC by adding a supplementary control loop into the active power (active power-frequency droop) as given by (1) or the DC voltage ( $\mathrm{V}_{\mathrm{DC}}$-frequency droop) control loop [6] [7]. A standard active power-frequency droop control block diagram is displayed in Fig. 3. Droop control may be used individually or may be combined with an additional integral term to remove steady state errors. Droop control is implemented or used for comparison in [5]-[15].

$$
\begin{gathered}
\Delta f=-R \cdot \Delta P \\
f \longrightarrow \Delta f \rightarrow \mathrm{K} \rightarrow \Delta \mathrm{P}
\end{gathered}
$$

\section{Fig. 3: Typical active power-frequency droop control}

Proportional only droop control is presented in [5] and is described as an easy control strategy to implement. A deadband is used to prevent the controller operating during normal frequency deviations. The use of proportional integral (PI) control is introduced with a VSC connecting an industrial load in [7] as displayed in Fig. 4. Case studies and simulation in [6] and [8] evaluate droop control and highlight the benefits of PI control over proportional only. Comparison between Vdc-frequency and active power-frequency droop provided in [6] displays that both methods improve frequency response. However, the power-frequency method which is a PI control displayed superior performance. In [8] the proportional controller is designed to produce a new frequency reference for the VSC output voltage based on the state of the DC voltage.

The use of two control modes is proposed in [9] which allow the VSC to operate in a normal generalised power-Vdc droop mode until a disturbance occurs, it then operates in an inertia mimicry mode. The inertia mimicry mode generates the references for the upper level control and will be discussed later. The control mode operation is determined by the specific needs of the network. Use of a supplementary frequency droop control in order for an interconnector to provide frequency response is shown to be effective in [10]. However, frequency disturbances may occur on the attached network if it is not a strong network. In [10], a powerfrequency droop is implemented on the interconnector to modulate the power based on the control presented in [7]. Similarly in [11], use of PI frequency control applied to the grid side VSC of a WPP is proposed to allow participation in frequency response.

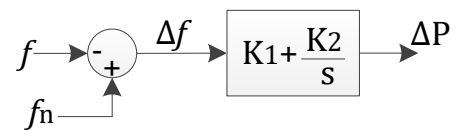

Fig. 4: Proportional integral control, adopted from [7].

An additional feedback loop is introduced in [12] to improve the response speed of the control system. The use of a PI droop control with a first order feedback loop is implemented as displayed in Fig. 5.

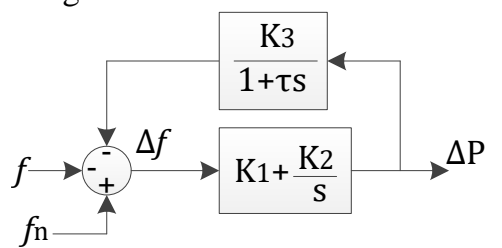

Fig. 5: PI with first order feedback, adopted from [12].

Two droop control strategies are proposed in [13] with the operating mode dependent on the status of the system frequency. If the system frequency is stable and only has small frequency variations, the controller uses a standard active power-Vdc droop control. If a significant frequency disturbance is detected, the controller switches to a frequency-Vdc droop control.

Frequency droop gain is determined by an estimation of the frequency deviation in [14] that enables the VSC to provide maximum support to the network. A low pass filter removes any high frequency oscillations and a deadband is included in the droop component as displayed in Fig. 6. The value of gain used by the droop control is obtained from a look table based on the frequency deviation.

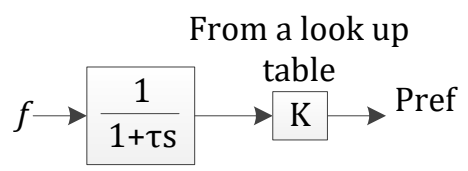

Fig. 6: Estimated droop gain control, adopted from [14]

\subsection{Derivative control}

A derivative controller uses the ROCOF $(d f / d t)$ of the grid as the measured variable to respond to disturbances [15]. This type of control scheme is commonly called synthetic inertia control and a generic block diagram is displayed in Fig. 7 and 
detailed in [16]. An inertia constant term $\mathrm{H}$ is included in this algorithm. Two possible synthetic control loop approaches are continuous and one shot as described in [16]. The continuous method is highly adaptive to the changing network frequency but requires more complex filtering, whereas, one shot control is based on initial ROCOF and is simpler to implement but does not continually adapt.

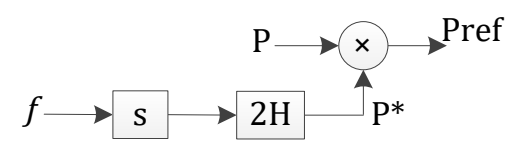

Fig. 7: Synthetic inertia controller, adopted from [16]

The derivative function may be provided by the use of a filter instead of a derivative block as described in [5] and [15]. A droop control combined with a lead-lag filter is presented in [15] and is designed to respond to the frequency error and also to the rate of change of the error signal. A block diagram of the proportional lead-lag controller is provided in Fig. 8. The use of a washout filter instead of a derivative term in the synthetic inertia frequency control loop is presented in [5]. A block diagram is displayed in Fig. 9 but note this would usually have an additional deadband to prevent unwanted operation.

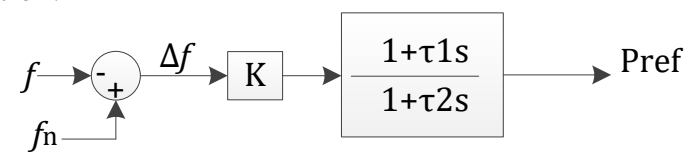

Fig. 8: Proportional lead-lag controller, adopted from [15]

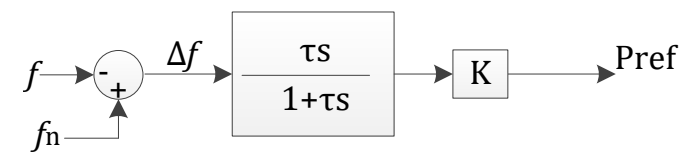

Fig. 9: Proportional controller with washout, adopted from [5]

The effect of different synthetic inertia controller activation schemes for a full converter wind turbine are presented in [17]. This work compares under frequency, continuously operating and maximum frequency gradient triggers to activate a synthetic inertia controller. Under frequency triggering of the synthetic inertia controller was demonstrated to be the most effective in the studied cases [17].

Modular multilevel converters (MMC) combined with energy storage are expected to be extremely relevant in future grids with high penetration of RES [18]. Investigations into the use of MMC attached to power intensive energy storage systems are presented in [18]. STATCOMs are widely used in the network and are commonly connected to the network using a step up transformer. The addition of storage connected to the STATCOM would allow transient stability support for the network [19]. Design of an active power controller is displayed in Fig. 10 and has two operating modes. The lower half responds to a frequency deviation based on a synchronous generator's governor droop controller with the addition of a lead-lag filter to provide faster frequency support. The upper half acts when the ROCOF exceeds a set triggering value.

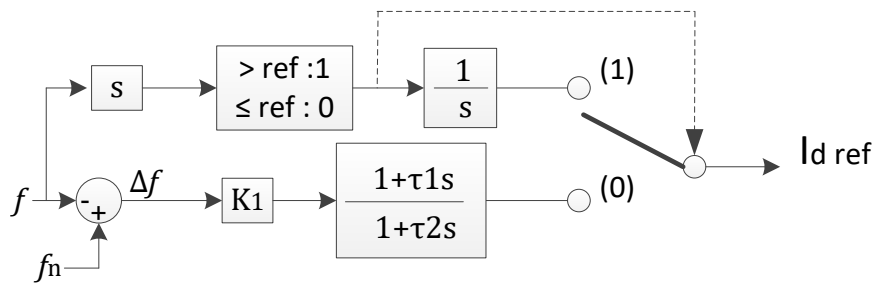

Fig. 10: Dual mode frequency control, adopted from [19]

\subsection{Inertia emulation control}

The term inertia emulation control has been used to describe the extraction of stored intrinsic energy in the VSC device or in the DC link in [5], [20] and [21]. Unlike other control strategies proposed, instead of using $\Delta f$ or $d f / d t$ as inputs, a measurement of the grid frequency can be used. The output of this control loop produces a DC voltage reference that is used as the setpoint in the voltage control loop [5]. The proposed method in [20] uses the energy stored in the HVDC capacitors and link to provide the inertial energy response. A simplified block diagram of the proposed inertia control loop is displayed in Fig.11. The constant K2 is given by (2) [5].

$$
K 2=\frac{4 H_{v s c} S_{v s c}}{N C}-V_{d c 0}^{2}
$$

The method proposed in [21] combines this inertia emulation control with a synthetic inertia controller. The aim of the method is to allow the inertia emulation controller to respond to sudden changes and to subsequently be supported by a WPP using a synthetic inertia controller. The proposal is that the communication delay that is present when extracting synthetic inertia from a WPP is overcome by utilising the intrinsic energy of the HVDC link [21]. However, the amount of stored energy available may be very limited and therefore restrict the application of this control strategy.

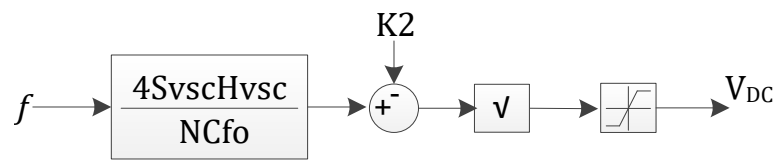

Fig. 11: Inertia emulation control loop [20]

\subsection{Virtual synchronous generation}

Operation of a VSC in a similar manner to a synchronous generator (SG) is often called a virtual synchronous generator (VSG) or a synchronverter. VSGs were proposed over a decade ago in order to provide some of the functionality and control of a synchronous generator as more power electronics are connected to the network [22]. VSGs are presented in [23] and this provides a background for their usage and application. VSGs use short term energy storage to provide fast response and then other energy sources to provide a further slower response. A block diagram of a typical VSG setup is displayed in Fig. 12 and an overview of control techniques is detailed in [22]. The definition of a synchronverter is introduced in [24] and highlights the differences from a VSG with the prominent difference being the lack of short term energy storage. 


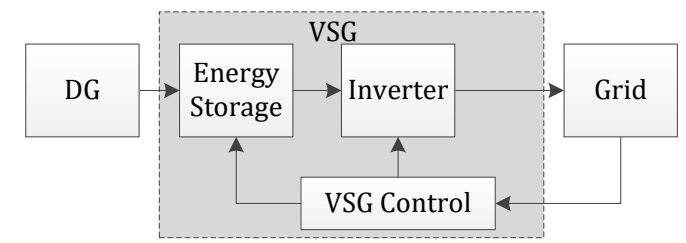

Fig. 12: Concept of a VSG [25].

Use of a VSG to enhance grid stability is discussed in [25] and [26] in which the swing equation is modelled to determine a virtual rotor angular velocity. Grid phase angle measurements and the determination of a virtual rotor phase angle allow a VSG to control the difference between the two. A governor control loop is applied to provide similar dynamics to a SG in [25] in which the governor is expressed as a first order lag element. Delays in determining the angular grid frequency are highlighted by [27] and a comparison with an ideal VSG is undertaken. The need for fast frequency detection is emphasised in order to operate on the desired ROCOF and not cause nuisance operation. For example, the use of a high ROCOF signal is used to trigger the VSG to output maximum power in [27] as shown by the Fig. 14.

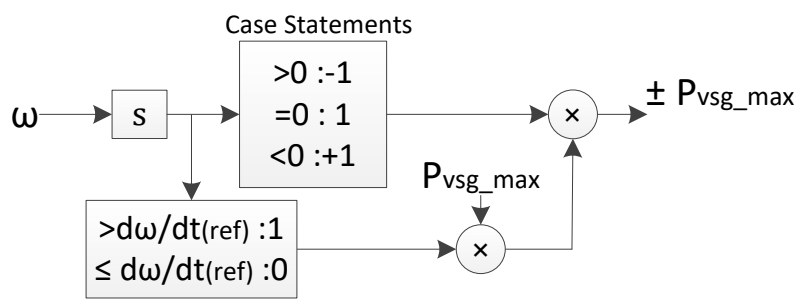

Fig. 14: VSG maximum output power algorithm [27].

A synchronous generator emulation control strategy (SGEC) is presented by the authors in [28] in which they implement a droop control component to allow the VSG to participate in primary frequency control. The implementation of the droop control in a VSG would allow it to coordinate with other VSGs when connected in an islanded or microgrid system making it suitable for low inertia systems.

\subsection{WPPs encompassing VSC}

The use of WPPs to provide frequency support has been extensively investigated in [29]-[31]. Supplementary control loops are used to release inertia from a wind turbine as proposed in [30] and [31]. Control of wind turbines for the purpose of frequency support is often achieved by releasing the kinetic energy by increasing the power output, which relies on operating in a de-loaded state, rather than maximum power point tracking to allow a power increase [29]. Coordinated control is required between the VSC and WPP to optimally provide frequency support. The strategy proposed in [30] increases WPP output proportional to $\Delta f$ by adding a droop control loop in parallel to the existing synthetic inertia controller. Optimal droop value tuning is required based on the composition of the power system that the WPP is connected to [30]. Commercial applications to enable a WPP to contribute to frequency response already exist such as GE Energy's WindInertia $^{\mathrm{TM}}$ controller [32].

\section{Coordinated and Supervisory Control}

Low inertia networks of the future will have an increased number of energy sources connected using power converters. These offer greater flexibility and operability than existing SGs [33] and may be configured as a MTDC network allowing power transfer between asynchronous networks, or may connect RES into an island network. This section provides a review of strategies applicable for controlling numerous power converters to support the system frequency.

\subsection{Multi terminal DC grids}

A co-ordinated strategy is applied in [34] that allows all asynchronous generation connected to the network to respond to a frequency disturbance in a single area without the use of a centralised controller. Each HVDC controller in the MTDC configuration monitors the frequency of its own area and the other areas to provide a frequency error signal. An assumption of a delay free communication is applied in the study. However, frequency control provided using a MTDC network is shown to be degraded as the communication time delay increases within [35]. Stability issues may arise when the time delay exceeds a certain threshold leading to undamped frequency oscillations that are more profound as values of controller gain increase. Autonomous local control is an alternative to overcome the impact of the delays that may cause instability described in [35].

The use of two droop operating modes is presented in [13] that allows each terminal to operate optimally based on the characteristics of the asynchronous networks. Control of power exchange is discussed in [36] and [37]. In [37], three power systems are connected using VSC-HVDC terminals in a trilateral configuration in order to improve frequency responses without adversely affecting the frequency in each asynchronous network. To prevent perturbing the frequency of a network when responding to a frequency disturbance in another network, a cooperative control concept is applied. Frequency containment is combined between two areas to enable fast response without threatening the frequency in the area providing the response. Similarly, a power exchange algorithm between two microgrids is introduced in [38] that uses the frequency measurement from both microgrids to determine the power reference for each VSC and direction of power flow between the microgrids. This strategy could produce a continually changing amount of frequency response available from the VSCs, making it difficult to determine the value of frequency response accessible to the system and reducing guarantees of system performance.

Two methods for determining the frequency setpoint for a VSC in a MTDC network are investigated in [39]. A weighted average frequency (WA- $f$ ) and local frequency measurement are compared. The WA- $f$ determines which asynchronous system's frequency is below/above the weighted average in order to determine each VSC power setpoint. The WA- $f$ measurement scheme was determined to be more beneficial over the local frequency measurement scheme for both AC and DC network stability. 


\subsection{Islanded operation}

Islanded systems may be viewed as microgrids and a classification of power converters embedded in microgrids is provided in [33]. Hierarchical control similar to existing layers of primary, secondary and tertiary is discussed in [33], [40] and [41]. Primary control in these cases is a local or decentralised control applied to the power converter that does not rely on communications with inherent delays. The ability of inverters connected in parallel to share load and crucially to respond simultaneously to network disturbances is important [42], [43]. Communication-free droop control schemes are implemented in these studies to share the load between inverters. Islanded microgrid inverter control is surveyed by [44] with detection of an islanded system noted as important to schedule the operation of inverters. Two strategies are proposed in [44] to manage all inverters connected to the network; single-master and multi-master. A multi-master requires a central controller to determine parameters for each master controller whereas a single-master controller sets the parameters for the slave devices. Lower control complexities and shorter communication delays have been shown to make local control the preferred method for providing frequency response by numerous authors.

System control using multiple agents may enable each component or energy source to communicate with each other and securely manage the network [45], [46]. In [46], a multiagent microgrid control system that adjusts the droop characteristics of each controller depending on the availability and state of charge of the other connected sources is presented. Multiple agents may not communicate with VSCs in the time frames required to enable frequency response, but could be used to provide more optimal coordinated control between VSCs over longer timescales, perhaps through appropriate gain scheduling. More complex centralised control strategies in the form of model predictive control (MPC) and particle swarm optimisation (PSO) are presented in [47] and [48]. These methods aim to determine the power injections required by each converter and also attempt to determine the optimal parameters for each converter. However, the practical applicability of such methods is severely limited by the processing time required for optimal decisions to be reached and the timescales in which this occurs.

\section{Summary}

It is expected that a future low inertia power system with power electronic connected energy sources will require local and supervisory control that interacts seamlessly to provide frequency support. A review of local supplementary frequency control strategies for VSC-HVDC has been presented, along with a brief overview of coordinated and supervisory control strategies that are applicable to MTDC grids (often originating from microgrid research).

Further investigation is needed to establish how numerous VSCs connected at the transmission level will respond to disturbances, particularly if differing control strategies are implemented. There is a potential for their interactions to degrade the level of system support they provide. Furthermore, although local droop-based strategies have proved most popular in this research area, it is yet to be established if this will provide an optimal level of system performance, or whether advanced strategies are needed.

\section{Acknowledgements}

The authors would like to thank the EPSRC and Siemens for supporting this work.

\section{References}

[1] "UK Greenhouse Gas Emissions". Department of Energy and Climate Change. [Online]. Available: https://www.gov.uk, [Accessed 12 ${ }^{\text {th }}$ March 2016], (2015)

[2] National Grid UK, "Enhanced Frequency Control Capability (EFCC)," 2015.

[3] A. Berizzi, "The Italian 2003 blackout," in Proc. IEEE PES Gen. Meeting, Colarado, USA, June 2004.

[4] Cigré. Working Group B4.57: Guide for the development of models for HVDC converters in a HVDC grid, 2014.

[5] A. Bucurenciu, M. Ndreko, M. Popov, and M. A. M. M. v. d. Meijden, "Frequency response using MTDC grids: A comparative study of common methods," in Proc. IEEE PowerTech, Eindhoven, Netherlands, June 2015.

[6] A. S. Elansari, S. J. Finney, J. Burr, M. F. Edrah, "Frequency control capability of VSC-HVDC transmission system," in Proc. 11th IET International Conf. on $A C$ and DC Power Transmission, Beijing, China, July 2015.

[7] C. Du, M. H. J. Bollen, E. Agneholm, and A. Sannino, "A New Control Strategy of a VSC-HVDC System for High-Quality Supply of Industrial Plants," IEEE Trans. on Power Delivery, vol. 22, no. 4, October 2007.

[8] C. Du, E. Agneholm, and G. Olsson, "Comparison of Different Frequency Controllers for a VSC-HVDC Supplied System," IEEE Trans. on Power Delivery, vol. 23, no. 4, April 2008.

[9] K. Rouzbehi, Z. Jiebei, Z. Weiyi, G. B. Gharehpetian, A. Luna, and P. Rodriguez, "Generalized voltage droop control with inertia mimicry capability - step towards automation of multiterminal HVDC grids," in Proc. Int. Conf. on Renewable Energy Research and App., Palmero, Italy, Nov. 2015.

[10] C. E. Spallarossa, Y. Pipelzadeh, and T. C. Green, "Influence of frequency-droop supplementary control on disturbance propagation through VSC HVDC links," in Proc. IEEE PES Gen. Meeting, Vancouver, Canada, July 2013.

[11] T. M. Haileselassie, R. E. Torres-Olguin, T. K. Vrana, K. Uhlen, and T. Undeland, "Main grid frequency support strategy for VSC-HVDC connected wind farms with variable speed wind turbines," in Proc. IEEE PowerTech, Trondheim, Norway, June 2011.

[12] K. Wang, J. Yao, J. Liu, S. Yang, and D. Zeng, "A generalized power control strategy with droop feedback for VSC-HVDC," in Proc. IEEE PES Gen. Meeting, San Diego, USA, July 2012.

[13] B. Silva, C. L. Moreira, L. Seca, Y. Phulpin, and J. A. P. Lopes, "Provision of Inertial and Primary Frequency Control Services Using Offshore Multiterminal HVDC Networks," IEEE Trans. on Sustainable Energy, vol. 3, no. 4, Oct. 2012.

[14] L. Shen, "Model Integration and Control Interaction Analysis of AC/VSC HVDC System," Ph.D. dissertation, Univ. of Manchester, Manchester, 2015.

[15] A. G. Endegnanew and K. Uhlen, "Global analysis of frequency stability and inertia in $\mathrm{AC}$ systems interconnected through an 
HVDC," in Proc. IEEE International Energy Conf., Leuven, Belgium, April 2016.

[16] M. Yu, A. Dyśko, C. D. Booth, A. J. Roscoe and J. Zhu, "A review of control methods for providing frequency response in VSC-HVDC transmission systems," in Proc. 49th International Universities Power Eng. Conf., Cluj-Napoca, Romania, Sep. 2014.

[17] F. M. Gonzalez-Longatt, "Activation schemes of synthetic inertia controller for full converter wind turbine generators," in Proc. IEEE PowerTech, Eindhoven, Netherlands, June 2015

[18] R. Alvarez, M. Pieschel, H. Gambach, and E. Spahic, "Modular multilevel converter with short-time power intensive electrical energy storage capability," in Proc. IEEE Electrical Power and Energy Conf., Ontario, Canada, Oct. 2015.

[19] E. Spahic, C. P. S. S. Reddy, M. Pieschel, and R. Alvarez, "Multilevel STATCOM with power intensive energy storage for dynamic grid stability - frequency and voltage support," in Proc. IEEE Electrical Power and Energy Conf., Ontario, Canada, Oct. 2015.

[20] Z. Jiebei, C. D. Booth, G. P. Adam, and A. J. Roscoe, "Inertia emulation control of VSC-HVDC transmission system," in Proc. Advanced Power Syst. Automation and Protection, International Conf., Beijing, China, Oct. 2011.

[21] A. Junyent-Ferr, Y. Pipelzadeh, and T. C. Green, "Blending HVDC-Link Energy Storage and Offshore Wind Turbine Inertia for Fast Frequency Response," IEEE Trans. on Sust. Energy, vol. 6, no. 3, July 2015 .

[22] S. D. Arco and J. A. Suul, "Virtual synchronous machines Classification of implementations and analysis of equivalence to droop controllers for microgrids," in Proc. IEEE PowerTech, Grenoble, France, June 2013.

[23] J. Driesen and K. Visscher, "Virtual synchronous generators," in Proc. IEEE PES Gen. Meeting, Pennsylvania, USA, July 2008.

[24] Q. C. Zhong and G. Weiss, "Synchronverters: Inverters That Mimic Synchronous Generators," IEEE Trans. on Ind. Electronics, vol. 58, no. 4, April 2011.

[25] K. Sakimoto, Y. Miura, and T. Ise, "Stabilization of a power system with a distributed generator by a Virtual Synchronous Generator function," in Proc. IEEE 8th International Conf. on Power Electronics and ECCE Asia, Jeju, Korea, May 2011.

[26] S. D'Arco, J. A. Suul, and O. B. Fosso, "A Virtual Synchronous Machine implementation for distributed control of power converters in SmartGrids," Electric Power Sys. Research, vol. 122, May 2015.

[27] V. Karapanos, P. Kotsampopoulos, and N. Hatziargyriou, "Performance of the linear and binary algorithm of virtual synchronous generators for the emulation of rotational inertia," Electric Power Sys. Research, vol. 123, June 2015.

[28] M. Guan, W. Pan, J. Zhang, Q. Hao, J. Cheng, and X. Zheng, "Synchronous Generator Emulation Control Strategy for Voltage Source Converter (VSC) Stations," IEEE Trans. on Power Syst., vol. 30, no. 6, Nov. 2015.

[29] F. Gonzalez-Longatt, E. Chikuni, and E. Rashayi, "Effects of the Synthetic Inertia from wind power on the total system inertia after a frequency disturbance," in Proc. IEEE Ind. Tech. International Conf., Cape Town, South Africa, Feb. 2013.

[30] J. V. d. Vyver, J. D. M. D. Kooning, B. Meersman, L. Vandevelde, and T. L. Vandoorn, "Droop Control as an Alternative Inertial Response Strategy for the Synthetic Inertia on Wind Turbines," IEEE Trans. on Power Syst., vol. 31, no. 2, March 2016.

[31] J. Ekanayake and N. Jenkins, "Comparison of the response of doubly fed and fixed-speed induction generator wind turbines to changes in network frequency," IEEE Trans. on Energy Conversion, vol. 19, no. 4, Dec. 2004.
[32] "WindINERTIA Tм Control". GE Energy. [Online]. Available: http://site.geenergy.com/prod_serv/products/renewable_energy/ en/downloads/GEA17210.pdf, [Accessed 28 $8^{\text {th }}$ Sept. 2016].

[33] J. Rocabert, A. Luna, F. Blaabjerg, P. Rodríguez, "Control of Power Converters in AC Microgrids," IEEE Trans. on Power Electronics, vol. 27, no. 11, Nov. 2012.

[34] J. Dai, Y. Phulpin, A. Sarlette, and D. Ernst, "Coordinated primary frequency control among non-synchronous systems connected by a multi-terminal high-voltage direct current grid," IET Generation, Transmission \& Distribution, vol. 6, no. 2, Feb. 2012.

[35] J. Dai, Y. Phulpin, A. Sarlette, and D. Ernst, "Impact of delays on a consensus-based primary frequency control scheme for AC systems connected by a multi-terminal HVDC grid," in Proc. Bulk Power System Dynamics and Control Symposium, Rio de Janeiro, Brazil, Aug. 2010.

[36] T. M. Haileselassie and K. Uhlen, "Power System Security in a Meshed North Sea HVDC Grid," Proc. IEEE, vol. 101, no. 4, April 2013.

[37] J. E. S. de Haan, C. E. Concha, M. Gibescu, J. van Putten, G. L. Doorman, and W. L. Kling, "Stabilising system frequency using HVDC between the Continental European, Nordic, and Great Britain systems," Sust. Energy, Grids and Networks, vol. 5, March 2016.

[38] M. Khederzadeh, H. Maleki, and V. Asgharian, "Frequency control improvement of two adjacent microgrids in autonomous mode using back to back Voltage-Sourced Converters," Int. Journal of Electrical Power \& Energy Syst., vol. 74, Jan. 2016.

[39] J. Renedo, A. García-Cerrada, and L. Rouco, "Active Power Control Strategies for Transient Stability Enhancement of AC/DC Grids With VSC-HVDC Multi-Terminal Systems," IEEE Trans. on Power Syst., vol. PP, no. 99, Jan. 2016.

[40] J. M. Guerrero, J. C. Vasquez, J. Matas, L. G. d. Vicuna, and M. Castilla, "Hierarchical Control of Droop-Controlled AC and DC Microgrids; A General Approach Toward Standardization," IEEE Trans. on Ind. Electronics, vol. 58, no. 1, Jan. 2011.

[41] C. Gavriluta, J. I. Candela, J. Rocabert, A. Luna, and P. Rodriguez, "Adaptive Droop for Control of Multiterminal DC Bus Integrating Energy Storage," IEEE Trans. on Power Del., vol. 30, no. 1, Feb. 2015.

[42] W. Chunsheng, L. Hua, Y. Zilong, W. Yibo, and X. Honghua, "Voltage and frequency control of inverters connected in parallel forming a micro-grid," in Proc. Power Sys. Technology, International Conf., Zhejiang, China, Oct. 2010.

[43] D. C. Raj and D. N. Gaonkar, "Frequency and voltage droop control of parallel inverters in microgrid," in Proc. Control, Instrumentation, Energy \& Commun., Kolkata, India, Jan. 2016.

[44] A. Llaria, O. Curea, J. Jiménez, and H. Camblong, "Survey on microgrids: Unplanned islanding and related inverter control techniques," Renewable Energy, vol. 36, no. 8, Aug. 2011.

[45] D. E. Olivares, C. A. Cañizares, and M. Kazerani, "A centralized optimal energy management system for microgrids," in Proc. IEEE PES Gen. Meeting, Detroit Michigan, USA, July 2011.

[46] A. Ghafouri, J. Milimonfared, and G. B. Gharehpetian, "Coordinated Control of Distributed Energy Resources and Conventional Power Plants for Frequency Control of Power Systems," IEEE Trans. on Smart Grid, vol. 6, no. 1, Jan. 2015.

[47] M. Imhof and G. Andersson, "Power system stability control using Voltage Source Converter based HVDC in power systems with a high penetration of Renewables," in Proc. Power Systems Computation Conf., Wroclaw, Poland, Aug. 2014.

[48] I. Y. Chung, W. Liu, D. A. Cartes, E. G. Collins, and S. I. Moon, "Control Methods of Inverter-Interfaced Distributed Generators in a Microgrid System," IEEE Trans. on Ind. Appl., vol. 46, no. 3, May 2010. 